\title{
The Impact of Digital Communication in the UAE "Qualitative study"
}

Reneh Abokhoza*

\begin{abstract}
Nowadays, Countries seek to implement E-government, which seeks to provide services and all government transactions electronically overcoming many of the difficulties facing the public and in pursuit of the growth and development of services, this is achieved through the effectiveness of digital communication through its websites, This study aims to identify the role of digital communication in influencing the effectiveness of e-government in the UAE by applying to Dubai and Sharjah, are keen to use their websites to market their services, but to varying degrees. The Dubai E-government has been the first to use digital communication. This is evidenced by the design of its websites and the effectiveness of digital communication with its public.
\end{abstract}

Key Words: E-government - digital communication - E-marking E-services

* Assistant professor -Al Falah University United Arab Emirates

Scientific Journal of Public Relations and Advertising Research - 20th Issue - July / December 20204031 
The Impact of Digital Communication in the UAE "Qualitative study"

\section{INTRODUCTION}

Now the internet occupies an important aspect of our daily lives for being the source of the important sources for the information and consideration along with this network an important source of knowledge. "e-government" refers to the delivery of information and services online through the internet or other digital means. The possibility to create a new space which can be invested in the marketing of goods or services resulted in increasing the competition in international markets, the development of technology to minimize the differences in the physical characteristics between competing products and the services available, and increasing awareness of corporate governance to the growing role played by digital communication in the continuation of competitive advantage and the ability to create sophisticated profitability and growth.

Digital communication helps to open the way for governments to market their goods and expertise, without discrimination between the head of the large or small money giant corporations which have limited resources where the advantage of its mechanisms ease of implementation and low-cost .

E-government has become an imperative necessity that must be pursued in every developed country that wants to keep abreast of the era of the digital revolution. E-government has a number of advantages, especially in the provision of services; it speeds up the process of accomplishing tasks in government institutions, it reduces costs, simplifies procedures while achieving transparency in management.

\section{Literature Review:}

Referring back to the literature on the importance of digital communication in E-government, most studies find positive effects. For example, ( Epstein \&others, 2016) found that the demographics of each city's population characteristics, the quality and level of internet access available, and the budgetary status and decisions of cities influence the offered e-government services in much more complicated ways than previously considered. Identifying these 
important factors in e-government adoption at the municipal level will facilitate future research on e-government adoption. Also they referred to inconsistent adoption of various e-government services by local governments, including some e-government services that have become universal (downloading government forms and applications), others that are practically nonexistent (chat rooms, instant messaging), and most were somewhere in between.

(li \& others, 2014) explained that adopting more e-services as compared to more constrained local governments-which might also be an indication of organizations responding to new public management reforms and pressures to do more with less, since eservices, such as online payment, delivery of records, requests to citizens, and online job applications, aim to reduce costs and increase performance.

(Micah, 2013) found that digital modes of communication had impacts on rationality which is the only dimension of interactivity is positively associated with relationship satisfaction. The results also show that affective commitment leads to advocacy in a B2B channel while trust and calculative commitment do not . (Park \& others, 2013) show that the central e-government units adopted many features for citizen participation via their websites. Hence, the traditional egovernment evaluations that are based on content indicate that the central e-government in Korea has already surpassed the information dissemination stage. However, it turns out that only the e-information index was relevant to citizens' actual usage and government units which provide more citizen-oriented information attract more citizens' usage, suggesting that citizens typically used the central e-government units to obtain information.

But (Wessels, 2012) concludes that there is ambiguity about the way identification links with identity in digital communication. This relates to the way people practice identity and in how they understand public-private boundaries. However, current everyday users do not explicitly refer reference with the internal and external process of identity in communication practices. The findings of (Alsaffar, E, 2011) study show that the use of e-procurement is becoming more widespread in the UAE. The UAE has been ranked 49th out of 184 with a total e-government index of 0.535 against a world average of

Scientific Journal of Public Relations and Advertising Research - 20th Issue - July / December 20204033 
The Impact of Digital Communication in the UAE "Qualitative study"

0.441 in the UN e-government 2010 survey. A comparative analysis of the survey shows that the UAE has an online services index of 0.251 against a world average of 0.286 ; an infrastructure index of 0.543 against a world average of 0.236 ; a human capital index of 0.819 against a world average of 0.797 ; and an e-participation index of 0.129 against a world average of 0.205 . The development trend of the e-government readiness index of the UAE is changing between 0.4736 and 0.5349 in the period from 2004 to 2010. (Thomas, 2010) explained that the capacity of instructors to improve online discourse is dependent on their understanding of its evolving structure and content. Social network analysis and content analysis provide methodological and technological means for identifying and characterizing evolving structural and substantive aspects of student communication. Highly refined techniques have been worked out by researchers over the years using time-intensive manual methodologies. (Bolivar and others, 2007) discussed to enhance the e-democracy process, there is a responsibility for governments to find ways to make their data more meaningful. A relevant way is to disclose this information using the new technologies to extend the dialogue between citizens and their governments about the use of resources. Those SRGs that have undertaken developments in governmental information systems could have encouraged creating a benchmarking process disclosing information on their Web sites.

\section{Digital Communication}

There are many concepts that refer to the use of digital technologies in the planning and implementation of its various work in view of the tremendous developments in the use of internet networks, including the field of business and productive companies. Its application was linked to a range of terms including electronic, ecommerce, e-management, e-marketing, e-government, and to determine the effectiveness of digital communication in various fields. These must be distinguished:

E-Business: it is the application of communication and information technologies supporting all business activities. It depends on the implementation of the work between two parties and the selling and buying activities, but extends further in relation to the financial, service, production and marketing activities.

Scientific Journal of Public Relations and Advertising Research - 20th Issue - July / December 2020403 
E-Commerce: is part of the e-business carried out by the electronic center, including commercial transactions where e-commerce provides the consumer the opportunity to identify the goods, products and services availabl. It also gives the customers the opportunity to order the product they wants and pay for it online as well. All of this must be done in the context of complete security and confidentiality in order to preserve user data. E-commerce implements and manages the business activities of products and services within different types, its main types are first, Business-to-Consumer, including onlineshopping. Second: Business-to-Business, integrations between producer and seller of products and goods, supply of products and performance of services. Third, government to consumer; government provides programs through the internet; the consumer has the right to use them. Fourth: Government-to-Business which the government purchased online.

\section{E-government}

Focuses on citizen service, many countries around the world have begun to adopt the concept of e-government by presenting very important information on its websites. A lot of government transactions and commercial transactions are conducted through the Internet. E-government services have the potential to increase service provision efficiency and effectiveness, particularly for local governments that are heavily focused on service delivery and interaction with citizens (Epstein, Ben, 2016). Most of the egovernment initiatives focus on the supply side, that is, the types of information and service that government can provide through the websites (Zhang, 2011)

The UAE Government announced in February 2010, sets the foundations to achieve UAE 2021, UAE Government strategy 20112013 consists of seven strategies. One of these strategies is dynamic government networks. The UAE gradually launched many e-services and also adopted practices complementary to the e-government program. (Obi, T., 2015)

\section{Aim of Study:}

The aim of the study is to identify how UAE government institutions use their websites to market their services and achieve their objectives. This study will also examine the effectiveness of those websites in the development of the performance of institutions.

Scientific Journal of Public Relations and Advertising Research - 20th Issue - July / December 20204035 
The Impact of Digital Communication in the UAE "Qualitative study"

To do so, a comparative study on the E-government of Dubai and the E-government of Sharjah is used to analyze the effectiveness of their websites. This study also aims to determine the variables that affect the modern communication trends in e-government and contribute to the development of future plans, which will reflect positively on their performance. Analyzing the most important issues and implications offered by E-Governments on their websites, and identifying the services provided to the public on the websites of E-governments is another aim of the study.

\section{Data and Sample:}

The UAE has adopted the e-government application in order to please the customers by finding a practical government to provide their customers with smart services of high quality, after a clear understanding of the needs of customers in line with their ambitions and meet their wishes.

The UAE consists of seven emirates: Abu Dhabi, Dubai, Sharjah, Ras Al Khaimah, Ajman, Umm Al Quwain and Fujairah. The study focuses on the northern emirates which include Dubai, Sharjah, Ajman, Ras Al Khaimah and Umm Al Quwain. The sample of the study was the websites of the governments of Dubai and Sharjah which have the largest population in the northern emirates. In 2015, the population of Dubai was 2,446,675 while the population of Sharjah was about 1,171,097 in 2012.

This study analyzed constructively the following websites:

- http://www.dubai.ae/ar/Pages/default.aspx

- http://www.sharjah.a e/index.aspx

The data used in this study was obtained during the period of March 1 through March 31, 2017.

\section{Methodologies Structural Analysis}

The aim of the study is to identify how UAE government institutions use their websites to market their services and achieve their objectives. This study will also examine the effectiveness of those websites in the development of the performance of institutions. Thus, Comparative approach deployed to identify the differences and agreement between e-governments in benefiting from information technologies to communicate effectively with the public and

Scientific Journal of Public Relations and Advertising Research - 20th Issue - July / December 2020403 
implement the mechanism of providing electronic services. Moreover, a Structural Analysis for websites, which is a detailed and functionally interconnected part; it is a type of analysis used to measure the effectiveness of websites in performing their functions through a set of standard features that are supposed to be available within the website. The study relied on it to measure the effectiveness of websites in performing their basic functions; interactive, communication, publicity and informing. And assistant functions that measure the ability of these websites to perform those functions effectively by measurement; display, usability, response, updated and transparency).

\section{Results}

\subsection{Basic Functions For Websites}

5.1.1 Interactive Function: this function measures the keenness of websites to activate their public participation through the below (15) features

Table (1) features of interactive function

\begin{tabular}{|l||c||c|}
\hline Features & \multicolumn{1}{|c|}{ E-governments } \\
\hline \hline Interactive & Dubai & Sharjah \\
\hline \hline Add comment & - & - \\
\hline \hline Survey & - & - \\
\hline \hline Download files & 1 & - \\
\hline \hline Search & 1 & 1 \\
\hline \hline Chat & - & - \\
\hline \hline e-mail & 1 & 1 \\
\hline \hline Telephone number & 1 & 1 \\
\hline \hline Fax & 1 & 1 \\
\hline \hline Address & - & - \\
\hline \hline Registration & 1 & 1 \\
\hline \hline E-services & 1 & - \\
\hline \hline Related Links & 1 & - \\
\hline \hline Listen to this page & 2 & $\mathbf{7}$ \\
\hline \hline Others & 1 & 1 \\
\hline \hline Contact Us & 12 & 1 \\
\hline \hline Total & 12 & - \\
\hline \hline
\end{tabular}


Interactive function was measured using (15) features. The results show that Dubai achieved (12) points while Sharjah only achieved 7 points for this function as explained below:

- $\quad$ Both websites do no provide features like adding a comment, taking a survey and chatting. Although the importance of those features relies on achieving effective communication with public.

Its noted that Dubai website provide feature (listen to this page) for blind users in two languages (Arabic, English), which supports their connection to the virtual world; this reflects the awareness of Dubai e-government to provide the blind users with facilities and helping them to achieve their rights to life. Also it provides the feature (Related Links), where it is easy for the browser to access a variety of alternatives in the field of research.

Also, The Sharjah website presented the traffic directions of the Sharjah e-Government in the region on the Google map, which makes it easy for the browser to reach them.

7.1.2 Communication Function: this function measures the ability of websites to connect the users and their requirements by providing some services that facilitate access to the goal by the following features.

Table (2) features of Communication function

\begin{tabular}{||c||c|c|}
\hline \multicolumn{1}{|c||}{ Features } & \multicolumn{2}{c|}{ Governments } \\
\hline \hline Communication & Dubai & Sharjah \\
\hline \hline Reference links & 1 & $\mathbf{0}$ \\
\hline \hline Hypertext & 1 & $\mathbf{0}$ \\
\hline \hline Internal links & 1 & $\mathbf{1}$ \\
\hline \hline Social media links & $\mathbf{4}$ & $\mathbf{3}$ \\
\hline \hline Read more & $\mathbf{1}$ & $\mathbf{0}$ \\
\hline \hline Nows & $\mathbf{1}$ & $\mathbf{0}$ \\
\hline \hline YouTube channel & $\mathbf{1}$ & $\mathbf{0}$ \\
\hline Total & $\mathbf{1 0}$ & $\mathbf{5}$ \\
\hline
\end{tabular}


Communication function was measured by using (6) features as a mark for each one and (n) numbers of social media links, the results show that Dubai achieved (10) points. While Sharjah achieved (5) points for this function as below:

Both of websites included (Internal links), those links are the hyperlinks that refer to another page on the same website. This is usually used in the interface Home which allows users to navigate the website and helps to set up a hierarchy of information for that website while helping the website get ranked in the search engines, making it easier for customers to browse within the website and increases their knowledge of electronic services. Also linked it through social media with other members with the same concerns. The Dubai EGovernment has been keen to communicate through the most famous social media platforms such as Facebook, Twitter, Insetgram and LinkedIn. The Sharjah E-Government on the other hand has used Facebook, Twitter and Instagram.

Website of Dubai government linked its users with various (Reference links) such as expo2020, Mohammed Bin Rashed Smart Majlis and Dubai weather. It also created a YouTube channel to view the latest innovative applications and explain how it is used.

7.1.3 Publicity Function: this function measures the ability of websites to reach the largest number of people to interact and benefit from e-government service

Table (3) features of publicity function

\begin{tabular}{|c|c|c|}
\hline features & \multicolumn{2}{|c|}{ E-governments } \\
\hline publicity & $\overline{\text { Dubai }}$ & Sharjah \\
\hline As a member & - & - \\
\hline Download Media & $\overline{1}$ & - \\
\hline Recommend a friend & - & - \\
\hline Share with friend & - & - \\
\hline like & - & - \\
\hline Share with us & - & - \\
\hline Evaluate & - & - \\
\hline Total & 1 & $\mathbf{0}$ \\
\hline
\end{tabular}


The publicity function was measured using (7) Features. Despite the importance of publishing function in achieving global spread and the ability to face competition and image management, it was achieved only through a few features. The results show that Dubai achieved (1) points while Sharjah could not achieve any point, as below:

The website of Dubai enables the users to download media files such as (Dubai Smart Gov. Magazine) which include the most important news, events and activities.

7.1.4 Informing Function: this function measures the ability of websites to provide all information and data that answers the public's queries and needs

Table (4) features of informing function

\begin{tabular}{|c||c||c||}
\hline \multicolumn{1}{|c||}{ feature } & \multicolumn{2}{c|}{ E-governments } \\
\hline \hline informing & Dubai & Sharjah \\
\hline \hline About & 1 & 1 \\
\hline \hline News & 1 & - \\
\hline \hline Newsletter & - & - \\
\hline \hline History & 1 & 1 \\
\hline \hline Official/ Leader list & 1 & 1 \\
\hline \hline FAQs & 1 & - \\
\hline \hline Documents & - & - \\
\hline \hline Services & 1 & 1 \\
\hline \hline Smartphone app & 1 & 1 \\
\hline \hline Total & $\mathbf{1}$ & - \\
\hline
\end{tabular}

On the other hand, Sharjah website ignored the importance of publicity function by deactivating all features.

Table (4) shows the results of structural analysis of any updated function which included (10) features; it was measured by giving a mark for each one, as below:

-Both of websites introduced themselves through (about Smart Dubai Gov.) and (about Sharjah). Also they were keen to display its (history); Dubai website presented it under (UAE government) and (about Dubai). While Sharjah website was presented under (Sharjah

Scientific Journal of Public Relations and Advertising Research - 20th Issue - July / December 202040310 
capital of culture). Further, the two websites provided (Official/ Leader list) through (Royal Websites) for Dubai and (Ruler of Sharjah) for the other. The websites were interested in explaining and clarifying electronic services provided to the public and reference to most used E-services.

-Superiority Dubai E-government accentuated the frequently asked questions (FAQs) to provide the needs of the public and save its time. In addition to presenting news (Dubai news \& events) and (the official magazine of Dubai smart GOV.) It is noted however that the magazine was not updated

(issue 149/March 2016). Finally it connected with its public by recommending Smartphone app downloading and provided it on its website.

7.2 The Assistant Function: Which Helps Websites To Apply Its Basic Functions Effectively

7.2.1-Display Function: this function measures different methods of displaying e-services and how to deal with them.

Table (5) features of Display function

\begin{tabular}{|c|c|c|}
\hline features & \multicolumn{2}{|c|}{ E-governments } \\
\hline Display & Dubai & Sharjah \\
\hline Specialized pages & 1 & 1 \\
\hline Audio file & - & - \\
\hline Animated Texts & 1 & 1 \\
\hline Animated photos & 1 & 1 \\
\hline Gallery & 1 & $\overline{1}$ \\
\hline Vedios & - & 1 \\
\hline live & - & - \\
\hline News bar & - & - \\
\hline RSS & - & - \\
\hline Multicolor & - & - \\
\hline Total & 4 & $\overline{5}$ \\
\hline
\end{tabular}

Table (5) shows the results of structural analysis of displaying function of websites, including (10) features as (1) mark for each one. So the total for the features (10) marks. The results showed that the 
website of Sharjah Government ranked first by (5) degrees, while the website of Dubai Government by (4) marks. The results explain that the websites were divided into specialized pages to facilitate the users to reach their goal. And the inclusion of animated texts that shows the most important electronic services available and how to benefit from them, as well as the inclusion of animated photos that illustrate the most famous landmarks, events and the activities development. On the other hand the website of Sharjah Government included a video that shows the most important landmarks, hotels and universities and the airport in Sharjah

However, these websites neglect many features of displaying functions, despite the importance of them such as including a news bar to present the most important events and latest developments. They also neglected (RSS), which enables the user to get the latest news as soon as they receive it instead of browsing the website and searching for it with last update. Also did not allow changing the colors of the website pages, which may bore the user while browsing it.

7.2.2-Response Function: this function measures the ability of websites to achieve effective communication with users by allowing the public to send their queries and respond to them quickly.

Table (6) features of Response function.

\begin{tabular}{|c|c|c|}
\hline feature & \multicolumn{2}{|c|}{ E-governments } \\
\hline \multirow{2}{*}{ Response } & Dubai & Sharjah \\
\hline & $\overline{\mathbf{0}}$ & $\overline{\mathbf{0}}$ \\
\hline
\end{tabular}

Response function was measured using: (6) marks for daily response, (4) marks to response within a week,(2) marks to response in more than a week. table (6) shows that both websites got no marks for this function because E-mails were sent to websites during the analysis period. The messages included an inquiry about the most important events to participate in, but no responses were received by all websites. These reflect the lack of interest in responding to messages of public and communicating with them. 
7.2.3-Usability Function: this function measures the achievement of interactivity through the possibility of better use of websites by providing them in a clear, systematic and easy to facilitate the user to browse.

Table (7) features of Usability function

\begin{tabular}{||c||c||c||}
\hline \multicolumn{1}{|c||}{ Feature } & \multicolumn{2}{|c|}{ E-governments } \\
\hline \hline Usability & Dubai & Sharjah \\
\hline \hline Availability & 4 & 1 \\
& & \\
\hline \hline Download home page & 4 & $\mathbf{2}$ \\
\hline \hline Website browse & 4 & $\mathbf{3}$ \\
\hline \hline Total & 12 & $\mathbf{6}$ \\
\hline
\end{tabular}

Table (7) refers to the structural analysis of the Usability Function, which includes three features: First, the "availability" feature which is measured by (1 mark) for each item (text only, print text, multilanguage, software for the blind, page zoom, pdf version, saving the page), which makes the total mark for this feature (7). The second feature is "Download home page" which is measured by (1 mark) when the loading speed is (0-20), (2 marks) when it is (21-40), (3 marks) when it is (41-60), (4 marks) when it is (61-80) ) and (5 marks) when the loading speed is (81-100). So maximum marks for the second feature is (5) . Third feature is "Website browse" which is measured by (1 mark) for each item; (a guide to browsing the website, a link to the home page on internal pages, the main link bar on each page, related topics), so the total mark for this feature is (4). Results show that :

"Availability": in addition to the main languages Arabic and English, Dubai E-Government printing pages of the website are available in a variety of languages: French, German, Russian, Chinese and Tagalog. Also the website provided software for the blind, and the ability to enlarge and reduce the size of the website page by changing the font size. While, Sharjah website only provide only two languages;

Arabic and English.

"Download home page": The speed of downloading for Dubai website is $66 / 100$, so it achieved 4 marks, while the speed of downloading for Sharjah website is 39/100, so it achieved 2 marks. 
"Website browse": Dubai E-Government provided all items for this feature, Sharjah website, on the other hand, ignored related topics but provided the other items.

7.2.4-Transparency Function: this function measures the level of transparency of the websites in presenting some privacy information to users in order to ensure trust and continuity of dealing with them

Table (8) features of Transparency function

\begin{tabular}{||c||c|c||}
\hline \multicolumn{1}{|c||}{ features } & \multicolumn{2}{c|}{ E-governments } \\
\hline \hline Transparency & Dubai & Sharjah \\
\hline \hline Privacy policy & $\mathbf{1}$ & - \\
\hline \hline Users counter & - & - \\
\hline \hline Total & $\mathbf{1}$ & $\mathbf{0}$ \\
\hline
\end{tabular}

Table (8) shows the results of structural analysis of the transparency function of websites, including two features as (1) mark for each one. The total of the features is (2) marks. The results granted the website of Dubai Government a mark as its privacy policy feature was allowed, while the website of the Government of Sharjah did not show that policy. Although This feature is very important in knowing the rights of the user and how the site they visit deals with its privacy. As for the second feature, neither of the websites indicated a counter on the site. But the website of Dubai Government displays the number of people interacting on the social networking sites such as: (33) likes on Facebook and 121 shares via other applications for the Arabic page. And (202) likes on Facebook and (183) shares via other applications for the English page.

Bolivar Indicated that in the move toward e-government which the public sector entities are currently undergoing, the disclosure of financial information can be extremely relevant for improving information transparency in the management of financial resources to render public sector services. This way, the citizens' needs for accountability can be efficiently met 
7.2.5- Updated Function: this function measures periodically updating the websites with the aim of providing the most up-to-date information in order to maintain communication with the public.

Table (9) features of Updated function

\begin{tabular}{|c||c||c|}
\hline feature & \multicolumn{2}{|c|}{ E-governments } \\
\hline \hline \multirow{2}{*}{ Updated } & Dubai & Sharjah \\
\cline { 2 - 3 } & $\mathbf{6}$ & $\mathbf{1}$ \\
\hline
\end{tabular}

Updated function was measured by using (6) marks for a daily update, (5) marks for an update within a week, (4) marks for an update in a week, (3) marks for an update within two weeks, (3) marks for an update within three weeks, (2) marks for an update within four weeks, and (1) mark for an update in more than a month. table (9) shows that the Government of Dubai is keen on updating the website daily, so it achieved (6) marks for the update function. The Government of Sharjah, on the other hand, did not update the website for more than a month, granting it (1) mark. It is possible that no change occurred in the services provided at that time, but no follow-up was reported.

Generally, this result shows Dubai Government's eagerness to present all that is new to its public and keeping them updated with the news and developments of its events.

\section{Research Contribution}

By referring back to the literature on the role of digital communication in E-government, the importance of the study is shown in:

1- Most of the studies focused on the nature of the e-services provided this study examines how these services are offered and their usability. By analyzing the infrastructure of these websites.

2- Current research add an implication to the leaders in UAE regarding how e-governments are applied in smart cities.

3- Explaining the importance of digital communication in activating e-government services. 


\section{Discussion}

Through the view of the results, it is clear to the researcher of this study that the Government of Dubai and Sharjah are keen to use their websites to market their services, but to a varying degree. The Dubai E-government has been the first to use digital communication. This is evidenced by the design of its websites and the effectiveness of its digital communication with the public. This network provides the government and its citizens the opportunities to connect away from normal procedures by creating a better working environment using ICTs in institutions and establishing an e-government infrastructure that helps to work easily through Streamlining, interaction and improvement of communication between the government and other institutions, through a set of basic functions and other assistance. first the basic functions are:

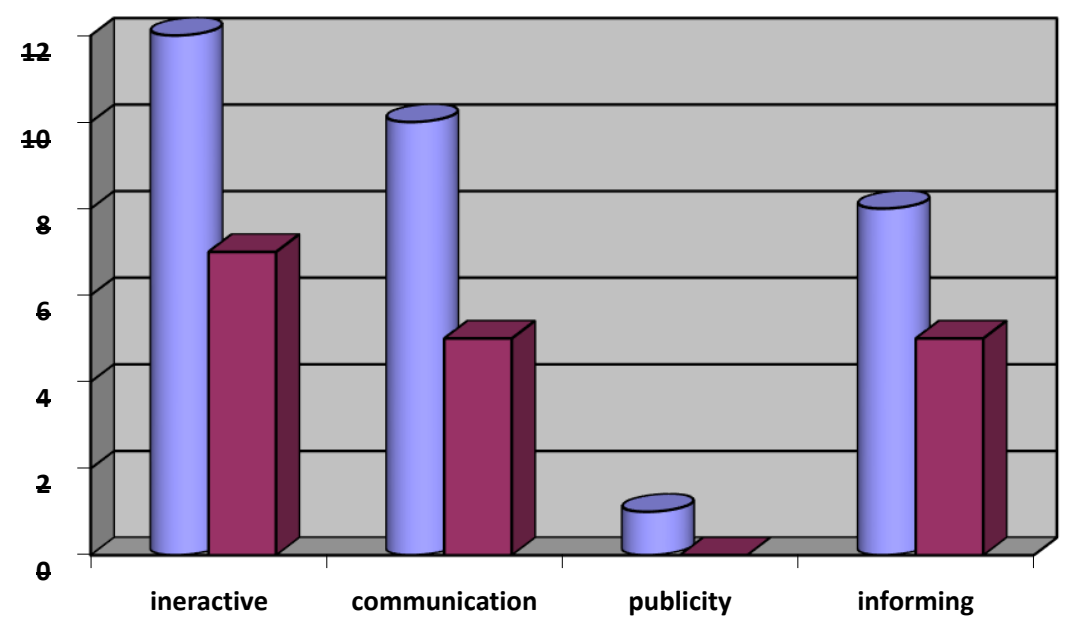

figure (1) show basic function for websites

1- Interactive function: Dubai E-government has made progress in its interactive function, by provided Most feature. But both of the websites ignored some of the features despite their importance in the 
interactive function, such as the "add comment" feature, which facilitates the study of public behavior and knowledge of its needs and desires and the modification of its services. This increases the volume of electronic transactions and provides them with convenience. Second, the "survey" function which helps in overcoming weaknesses and follow-up needs of the public and solving any problems they might face which ultimately leads to eliminating any obstacles during electronic transactions. Third, the "chat" feature which helps officials in keeping track of users and in keeping them confidential.

2- Communication Function: as shown above, the Dubai Egovernment made a significant development in applying the features of communication function, which reflects its awareness of the importance of continuous good communication with customers and fulfilling their desires. This supports interactive web sites.

3- publicity Function: generally, the websites ignored most features of this function in spite of its importance in promoting government services and expanding relations to reach the public. This is also a good link between the government and its public.

4- Informing Function: Dubai E-government has been able to use the informing function well in communicating with the public. This allows the dissemination of information about its E-services, not only in response to their requests but also in initiatives. It also helps in achieving interaction and communication between the government and the public and various institutions, in order to facilitate and improve government performance, making it an effective mechanism to make a fundamental shift in the culture of implementation of services and government transactions. 


\section{Second the assistant function are :}

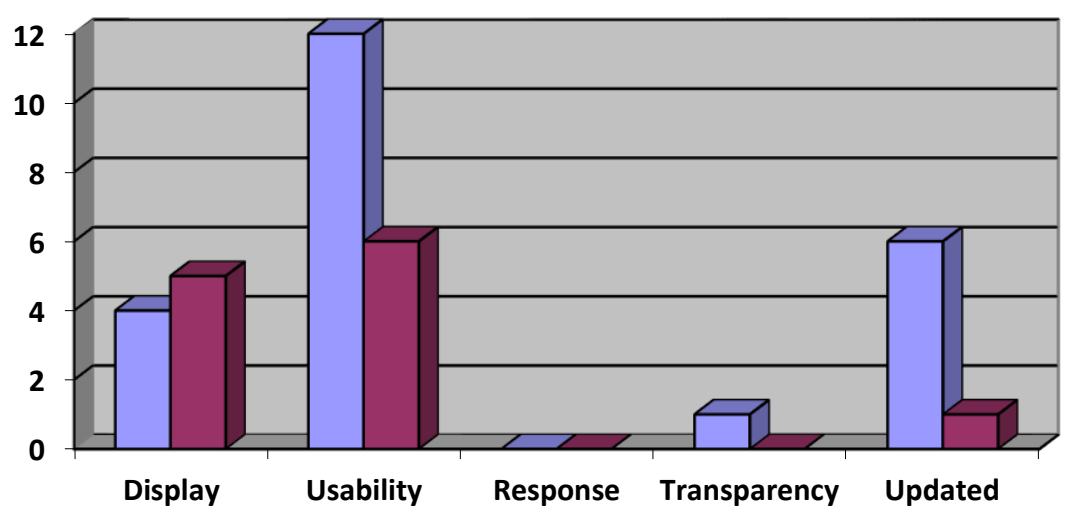

Figure (2) shows assistant functions

5- Display Function: The Sharjah Government website showed interest in applying the display function through showing video files. However, this is not enough to communicate with the public. So both websites need to re-evaluate the activation of display function and develop its features to be in line with the needs of the public.

6- Usability Function: relatively both websites are keen on applying the features of usability function that makes it easy to download the page, thus making it easier for users. There are links to the home page and the main link bar on each page and the availability of related topics, which shows the interest of these E-governments in providing everything that interests their public through their websites to satisfy the users.

7- Response Function: both websites do not show interest in responding to messages from the public. Thus it is recommended that these websites must provide important links and create icons of service to facilitate the visitors, by opening direct communication channels with the citizen and assigning staff to respond quickly to the requirements of the public. 
8- Transparency Function: privacy policy feature on the Dubai egovernment website was allowed, which shows the E-government's belief in the role of integrity in the development of various practices in websites, and commitment to values in the performance of various functions.

9- Updated Function: despite the importance of this function to achieve effectiveness on the websites through the provision of the latest and always gain public interest in browsing permanently, Sharjah E-government ignored this importance and did not update its website for over a month. The study recommends the importance of updating information and the services provided continuously, to develop websites, attention to their designs and external form to achieve the effectiveness of E-government. 
The Impact of Digital Communication in the UAE "Qualitative study"

\section{REFERENCES}

- Alsaffar, E. (2011). A method for an e-procurement adoption pattern in an emerging economy (Doctoral dissertation, University of Reading,.United Kingdom)

- Chen, Y. C., \& Zhang, J. C. (2012). Citizen-centric E-government Performance: Satisfaction with E-information. Electronic Government, An International Journal, 9(4), 388-402.

- Epstein, Ben., Bode, Leticia. and Connolly, Jennifer.(2016) "Why Your Local Government Offers So Many (Or So Few) E-government Services", Paper presented at the annual meeting of the American Political Science Association Annual Meeting, TBA, Philadelphia, PA.

- Li, M. H., \& Feeney, M. K. (2014). Adoption of electronic technologies in local US governments: Distinguishing between e-services and communication technologies. The American Review of Public Administration, 44(1), 75-91., p87

- Murphy, M. (2013). Communication and interactivity in B2B relationships(Doctoral dissertation, Florida Atlantic University Boca Raton, Florida) p84

- Obi, T., \& Iwasaki, N. (2015). A Decade of World E-Government Rankings (Vol. 7). IOS Press. P170

- Park, S., Choi, Y. T., \& Bok, H. S. (2013). Does better e-readiness induce more use of e-government, Evidence from the Korean central e-government. International Review of Administrative Sciences, 79(4), 767-789.

- Rodriguez Bolivar,M. P.,Caba Perez, C \& Lopez Hernandez,A.M.(2007). EGovernment and public financial reporting: the case of Spanish regional governments. The American Review of Public Administration, 37(2), 142-177. p163

- Thomas, D. A., Sa, L., Li, Z., \& Maddux, C. D. (2010), Structure and substance in digital communication. Journal of Educational Technology Systems, 38(3), 313340 .

- Wessels, B. (2012). Identification and the practices of identity and privacy in everyday digital communication, New Media \& Society, 1461444812450679. p1264

- http://www.expo2020dubai.ae/

- http://www.mbrmajlis.ae/

-http://www.dubaiairports.ae/weather

- https://www.youtube.com/dubaismartgov

-The speed of downloading websites was measured through

https://developers.google.com/speed/pagespeed/insights/

- http://www.dubai.ae/ar/Pages/Default.aspx available at 28/3/2017

- https://government.ae/en/about-the-uae/the-seven-emirates/dubai

- https:/government.ae/en/about-the-uae/the-seven-emirates/sharjah 